MATEC Web of Conferences 39, 03005 (2016)

DOI: $10.1051 /$ matecconf/20163903005

(C) Owned by the authors, published by EDP Sciences, 2016

\title{
Determination of three physical properties of quinoline ionic liquids with hexafluorophosphate
}

\author{
Dan Tang ${ }^{1}$, Litao Wang ${ }^{1}$, Shun Yao ${ }^{1}$, Yanwen Chen ${ }^{1}$, Daocai Wang ${ }^{1}$ and Hang Song ${ }^{1, a}$ \\ ${ }^{1}$ Department of Pharmaceutical and Biological Engineering, Sichuan University, Chengdu, China
}

\begin{abstract}
Densities of one acidic ionic liquid (IL) Quinolinum hexafluorophosphate ([HBpy][ $\left.\mathrm{PF}_{6}\right]$ ), and four neutral dicationic ionic liquids (ILs) based on quinoline and hexafluoro-phosphate and linked with poly(ethylene glycol) (PEG): ([PEG $\left.{ }_{200}-\mathrm{DIL}\right]\left[\mathrm{PF}_{6}\right]_{2},\left[\mathrm{PEG}_{400}-\mathrm{DIL}\right]\left[\mathrm{PF}_{6}\right]_{2},\left[\mathrm{PEG}_{800}-\mathrm{DIL}\right]\left[\mathrm{PF}_{6}\right]_{2}$ and $\left[\mathrm{PEG}_{1000}-\mathrm{DIL}\right]\left[\mathrm{PF}_{6}\right]_{2}$ ) were determined. In addition, the solubilities of six ILs in six lower alcohols, water, acetonitrile and diethyl ether were measured at 288.15 $\mathrm{K}$; and the hydroscopicity of above five ILs were measured at the temperature of $298.15 \mathrm{~K}$ and relative humidity of $79 \%$ for $24 \mathrm{~h}$. Densities of five ionic liquids were determined between 283.15 and $333.15 \mathrm{~K}$. Then the densities of five binary system (ILs/acetonitrile) were explored between 283.15 and $333.15 \mathrm{~K}$, the type of the ionic liquid, the concentration of five ILs in $\mathrm{CH}_{3} \mathrm{CN}$, and the effect of temperature on the binary systems, were correlated with the measured data.
\end{abstract}

\section{Introduction}

Ionic liquids have some unique physicochemical properties due to their special structure, such as high thermal stability, high ionic conductivity, viscosity and good solubility properties. Many of them are nonflammable or non-volatile, it is considered to be the most promising functional material in green chemistry and clean technology, which is widely used in various fields [1-3]. As a common chemical material, poly (ethylene glycol) (PEG) also has good stability (thermal, chemical), no or null vapour pressure, high thermal and ionic conductivity, etc.; PEG is also inexpensive and widely available. Those incorporating PEG moieties into ILs $\left(\mathrm{IL}_{\mathrm{PEG}}\right)$ can make the ILs share their properties [4], which can yield a new appealing group of properties with the structural modification of cation and anion in ILs. Despite the great possibilities in application of the ILPEG system, there are limited reports about their properties or fundamental data $[4,5]$. Recently, ILs shows great prospect as extraction solvents in liquidliquid extraction, solid-liquid extraction and liquid-phase extraction because of their good solubility property $[6,7]$, and they play an important role in extracting compounds such as protein [8], heavy-metal ions [9], traditional Chinese medicine from complicated samples [10], and they can improve selectivity remarkably as well as efficiency. Furthermore, it was reported that waterimmiscible $\mathrm{BF}_{4}$-based ILs can be used in the extraction of metal ions from wasted water [11].

In our previous work, five ionic liquids: $[\mathrm{HBpy}]\left[\mathrm{PF}_{6}\right]$ (1), ([PEG $\left.{ }_{200}-\mathrm{DIL}\right]\left[\mathrm{PF}_{6}\right]_{2}$ (2), $\left[\mathrm{PEG}_{400}-\mathrm{DIL}\right]\left[\mathrm{PF}_{6}\right]_{2}$ (3), $\left[\mathrm{PEG}_{800}-\mathrm{DIL}\right]\left[\mathrm{PF}_{6}\right]_{2}$ (4) and $\left[\mathrm{PEG}_{1000}-\mathrm{DIL}\right]\left[\mathrm{PF}_{6}\right]_{2}(\mathbf{5})$ were synthesized to pre-treat isatids extract and preconcentrate indigotin and indirubin [12], and study shows that the existence of ILs improved the efficiency of extraction [13]. For their further study and application, it is important to investigate the physicochemical properties of these ILs. 1, 2, 3, 4 and 5 are all soluble in methanol, ethanol, isopropanol, n-propanol, n-butanol, isobutanol, while they were insoluble in ether which is low polar solvent. Especially they are all very soluble in acetonitrile, therefore this paper further investigated the densities of ILs and solution with acetonitrile, and correlated the measured data with temperature and concentration of ILs, which is expected to provide a foundation for potential applications of these five novel ionic liquids.; Meanwhile, solubility of these five ILs in water is not negligible, so this work also investigated their hydroscopicity; what's more, the investigation of the relationship between their structure and physicochemical properties can also guide or inspire the design of new ionic liquids as well as their synthesis, so study about physicochemical properties of ILs is of great importance.

\section{Experimental}

\subsection{Materials and Reagents}

Quinoline (98\%) was purchased from John Hong chemical technology Co.LTD (Shanghai, China). Methanol, ethanol, n-propanol, isopropanol, n-butanol, isobutanol, ether, PEG-200, PEG-400, PEG-800, PEG1000 , and $\mathrm{KPF}_{6}$ was all of $\mathrm{AR}$ grade (mass fraction purity of $99.5 \%$ ), and acetonitrile was of HPLC grade (mass

\footnotetext{
${ }^{\mathrm{a}}$ Corresponding author: hangsong@scu.edu.cn
} 
fraction purity of 99.9\%), and all were purchased from Kelong Chemical Reagents Factory (Chengdu, China). Deionized water was obtained by the UPR-I-5T water purification system from Ulupure Technology Co. Ltd (Chengdu, China). [HBpy] $\left[\mathrm{PF}_{6}\right], \quad\left[\mathrm{PEG}_{200}-\mathrm{DIL}\right]\left[\mathrm{PF}_{6}\right]_{2}$, $\left[\mathrm{PEG}_{400}-\mathrm{DIL}\right]\left[\mathrm{PF}_{6}\right]_{2}, \quad\left[\mathrm{PEG}_{800^{-}} \mathrm{DIL}\right]\left[\mathrm{PF}_{6}\right]_{2}$ and $\left[\mathrm{PEG}_{1000^{-}}\right.$ $\mathrm{DIL}]\left[\mathrm{PF}_{6}\right]_{2}$ were synthesized referring to previous literature [12], and the structure of ILs is displayed in figure 1 and figure 2 .

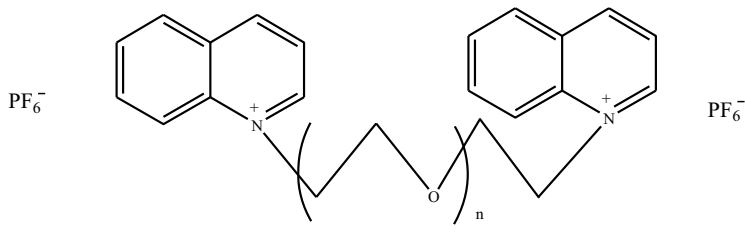

Figure 1. The structure of dicationic ionic liquids (ILs) based on quinoline and hexafluoro-phosphate and linked with PEG, when, $\mathrm{n}=200$, $\left[\mathrm{PEG}_{200}-\mathrm{DIL}\right]\left[\mathrm{PF}_{6}\right]_{2} ; \mathrm{n}=400$, $\left[\mathrm{PEG}_{400}-\mathrm{DIL}\right]\left[\mathrm{PF}_{6}\right]_{2}$; $\mathrm{n}=800,\left[\mathrm{PEG}_{800}-\mathrm{DIL}\right]\left[\mathrm{PF}_{6}\right]_{2} ; \mathrm{n}=1000,\left[\mathrm{PEG}_{1000}-\mathrm{DIL}\right]\left[\mathrm{PF}_{6}\right]_{2}$.<smiles>c1ccc2ncccc2c1</smiles>

$\mathrm{PF}_{6}^{-}$

Figure 2.The structure of $[\mathrm{HBpy}]\left[\mathrm{PF}_{6}\right]$

\subsection{Methods}

\subsubsection{Solubility of ionic liquids in various solvents}

A certain amount IL was placed in a dry jacketed glass reaction flask, and a thermostatic water-circulator bath was used to keep it at the temperature of $298.15 \mathrm{~K}$. Then the solvent was slowly added into the flask, until the ionic liquid was completely dissolved; the initial mass of solvent was precisely measured. The solubility of ILs in solvents (water, menthol, ethanol, isopropanol, npropanol, n-butanol, isobutanol, diethyl ether) was calculated as follows:

$$
x_{i}=\left(m_{1}-m_{2}\right) / v
$$

Where $m_{1}(\mathrm{~g})$ and $m_{2}(\mathrm{~g})$ represent the mass of the initial solvent and solvent left; respectively, $v(\mathrm{~mL})$ is the volume of the solvent, consequently $x_{i}\left(\mathrm{mg} \mathrm{mL}^{-1}\right)$ represents the solubility of ILs. According to the criterion definitions in Chinese Pharmacopoeia (2015 edition), "insoluble" means that $1 \mathrm{~g}$ of solute is not completely dissolved in more than $10000 \mathrm{~mL}$ of solvent.

\subsubsection{Hydroscopicity}

In this study, the hydroscopicity of five ILs was studied at an environment where temperature was $298.15 \mathrm{~K}$ and relative humidity was $60 \%$. To eliminate the interference of water and volatile coexisting compounds before hydroscopicity experiments, all ILs were dried under vacuum at $333.15 \mathrm{~K}$ for $72 \mathrm{~h}$; Then the five ILs were evenly spread on open Petri dishes at temperature of 298.15 K, then placed in the air with stable relative humidity, after each interval of time $(1 \mathrm{~h}, 2 \mathrm{~h}, 4 \mathrm{~h}, 8 \mathrm{~h}, 12$ $\mathrm{h}, 18 \mathrm{~h}, 24 \mathrm{~h})$, the increased weight $\left(M_{t}\right.$, accurate to 0.1 $\mathrm{mg}$ ) of these five ILs were determined [14], and then hydroscopicity within $24 \mathrm{~h}$ was given by the equation (2).

$$
\text { Hydroscopicity }=\left(M_{t}-M_{0}\right) / M_{0} \times 100 \%
$$

Where $M_{t}$ ( $\mathrm{g}$ ) represents the mass of Petri dishes when time is $1 \mathrm{~h}, 2 \mathrm{~h}, 4 \mathrm{~h}, 8 \mathrm{~h}, 12 \mathrm{~h}, 18 \mathrm{~h}, 24 \mathrm{~h}$; and $M_{0}$ (g) represents the initial mass of Petri dishes. ILs was measured at atmospheric pressure from $283.15 \mathrm{~K}$ to $333.15 \mathrm{~K}$; the temperature was kept constant at each point for 60 minutes. The measurement was repeated three times and average experimental values were obtained; the precision of the measurements was $\pm 0.01 \mathrm{~g} \mathrm{~cm}^{-3}$. The density was then obtained by dividing the mass of the fluid by the corrected pycnometer volume.

\subsubsection{Density}

Density of ILs and ILs solution was determined with a 10 $\mathrm{mL}$ pycnometer at different temperatures. First of all, the pycnometer was calibrated with acetonitrile to obtain the exact volume, and the density of acetonitrile was referenced from the literatures $[15,16]$. During the experiment, the temperature was maintained within \pm $0.05 \mathrm{~K}$ in a thermostatic water-circulator bath; the density of ILs was measured at atmospheric pressure from 283.15 $\mathrm{K}$ to $333.15 \mathrm{~K}$; the temperature was kept constant at each point for 30 minutes. The measurement was repeated three times and average experimental values were obtained; the precision of the measurements was $\pm 0.01 \mathrm{~g}$ $\mathrm{cm}^{-3}$. The density was then obtained by dividing the mass of the fluid by the corrected pycnometer volume.

\section{Results and discussion}

\subsection{Solubility}

Solubility data of five ionic liquids in various solvents under room temperature $(298.15 \mathrm{~K})$ were showed in figure 3. Figure 3 shows that these five ILs are soluble in strong polar organic solvent (alcohols) while they are insoluble in ether which is low polar solvent and have poor solubility in water, particularly $\mathbf{2}$ is insoluble in water. Fig. 3 shows that the solubility of five ILs in six mono-alcohols decreased as the polarity decreased; What's more, in each one of six solvents, the solubility of PEG-based dicationic ILs accordingly increases with an increase of the chain length of the ILs; the above results are caused by multi-effect of the hydrogen bonding, the polarity of solvents and the stereo-hindrance. The solubility of the quinolinum hexafluorophosphate mainly influenced by the interactions of hydrogen bonding, existing between fluorine atom and the lone electron pairs of the solvents, hydrogen bonding also existing between the quinolinum ring and the lone electron pairs of solvents. Except above interactions, the solubility of the PEG-based ILs is also influenced by hydrogen bonding generated by the lone electron pairs of PEG-fragment and water, as well as the stereo-hindrance effect of the PEG 
chain; on one hand, with the PEG chain increasing, the stereo-hindrance effect is smaller therefore the interactions are stronger, on the other hand, the stereohindrance also weakens the hydrogen bonding force between the quinolinum ring and solvents form.

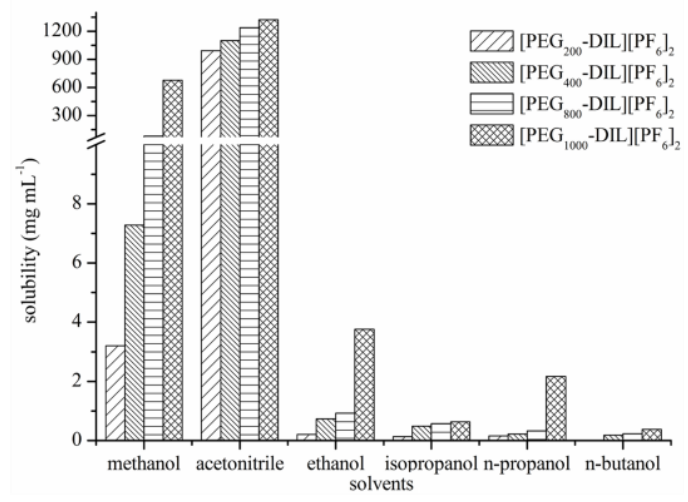

Figure 3. Solubility values of four PEG twins ILs in six solvents under room temperature $(298.15 \mathrm{~K})$.

\subsection{Hydroscopicity}

The hydroscopicity of five ILs at an environment where temperature was $298.15 \mathrm{~K}$ and relative humidity was $60 \%$ is presented in table 1 .

Table 1. Hydroscopicity of the ILs in air at ambient temperature $(298.15 \mathrm{~K})$ and relative humidity $(79 \%)$

\begin{tabular}{|c|c|c|c|c|c|}
\hline $\mathrm{t} / \mathrm{h}$ & $\mathbf{1}$ & $\mathbf{2}$ & $\mathbf{3}$ & $\mathbf{4}$ & $\mathbf{5}$ \\
\hline 1 & 0.0634 & 0.3654 & 0.6845 & 0.8873 & 1.1983 \\
\hline 2 & 9.5902 & 8.0390 & 8.6056 & 10.2273 & 12.7210 \\
\hline 4 & 9.5057 & 8.0999 & 8.6338 & 10.3099 & 12.8351 \\
\hline 6 & 9.6536 & 8.1405 & 8.6620 & 10.3512 & 12.8637 \\
\hline 8 & 9.6540 & 8.1811 & 8.9718 & 10.4339 & 12.9778 \\
\hline 12 & 9.7803 & 8.2420 & 9.2817 & 10.6198 & 13.3771 \\
\hline 24 & 9.8014 & 8.4856 & 10.4930 & 11.5496 & 13.8620 \\
\hline
\end{tabular}

Figure 4 indicates that the longer time the ILs was in air, the greater the absorbed water amount of ILs was; when the time exceeded two hours, the water absorption tended to increase slowly and absorption saturation would be achieved. Among these five ILs, 5 has the maximum water absorption, and the water-absorbent rate in initial $2 \mathrm{~h}$ reached $6.3605 \mathrm{~g} /$ (min g), meanwhile 2 has the weakest hydroscopicity; what's more, 1 has the maximum hydroscopicity is not the maximum, which is between that of $\mathbf{3}$ and $\mathbf{4}$. According to previous solubility and hydroscopicity data, there was certain relationship between hydroscopicity and solubility in water; the above results are also caused by multi-effect of the hydrogen bonding and the stereo-hindrance as solubility in water. The hydroscopicity of the $[\mathrm{HBpy}]\left[\mathrm{PF}_{6}\right]$ mainly influenced by the interactions of hydrogen bonding, existing between fluorine atom and the lone electron pairs of water, hydrogen bonding also existing between the quinolinum ring and the lone electron pairs of water. And the hydroscopicity of the PEG-based ILs is increased because of the hydrogen bonding generated by the lone electron pairs of PEG-fragment and water, while decreased by the stereo-hindrance effect of the PEG chain.

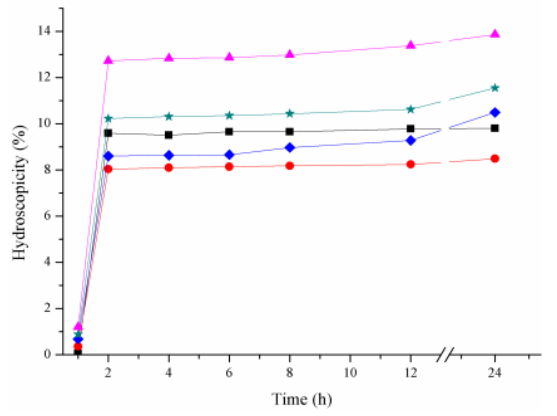

Figure 4. Hydroscopicity of the ionic liquids in air under room temperature

$* \boldsymbol{\Delta}\left[\mathrm{PEG}_{1000}-\mathrm{DIL}\right]\left[\mathrm{PF}_{6}\right]_{2}, \star\left[\mathrm{PEG}_{800}-\mathrm{DIL}\right]\left[\mathrm{PF}_{6}\right]_{2}, \boldsymbol{\|}[\mathrm{HBpy}]\left[\mathrm{PF}_{6}\right]_{2}$,

$\bullet\left[\mathrm{PEG}_{400}-\mathrm{DIL}\right]\left[\mathrm{PF}_{6}\right]_{2}, \bullet\left[\mathrm{PEG}_{200}-\mathrm{DIL}\right]\left[\mathrm{PF}_{6}\right]_{2}$

\subsection{Density}

Density is one of the most important physicochemical properties of ILs, and in most cases, temperature has significant influence on densities of ILs. In the study, the densities of four ILs were measured at standard atmospheric condition in the range of $263.15 \sim 313.15 \mathrm{~K}$.

Table 2. Comparison of experimental density $(\rho)$ and density with literature values for acetonitrile

\begin{tabular}{|l|c|c|c|}
\hline \multirow{2}{*}{ T/K } & \multicolumn{2}{|c|}{$\rho /\left(\mathbf{g ~ c m}^{-\mathbf{3}}\right)$} & ARD/ (100\%) \\
\cline { 2 - 4 } & Expt. & Lit. & \\
\hline 293.15 & 0.78179 & 0.7823 & 0.0654 \\
\hline 303.15 & 0.77134 & 0.77144 & 0.0123 \\
\hline 313.15 & 0.75824 & 0.76068 & 0.3203 \\
\hline 323.15 & 0.75053 & 0.74973 & 0.1112 \\
\hline 333.15 & 0.74052 & 0.73819 & 0.3160 \\
\hline
\end{tabular}

The density data for the investigated ILs is presented in Table 2 and Figure 5. Different concentrations of binary mixtures (ionic liquid/acetonitrile) at atmospheric pressure in the density data from $283.15 \mathrm{~K}$ to $313.15 \mathrm{~K}$ are listed in Table 2.The density trend of the ionic liquid in the temperature range is shown in Figure 5 7. In order to investigate the reliability of density data in this work, a comparison is firstly made for the pure components in Table 2 between the experimental densities together with densities reported in the literature. It's obvious that the values for acetonitrile in different temperature agree well with those reported in the literature. Therefore, it can be proved that the density data determined in this work are acceptable. Experimental data of density are collected in Table 3 and 4 for 1, 2, 3 and 4, and their mixtures over the concentration of $0.01,0.02,0.04,0.06 \mathrm{~g} \mathrm{~mL}^{-1}$.

All of the density data in Figures 5 7 showed a tendency of decline with the increase of temperature. With temperature increasing, intermolecular distance is longer, and the liquid volume becomes larger. As a result, the density is lower. For the four ILs with same anion and different PEG chain length of cation, Figure 4 shows that density will decrease with the increase of chain length, and the density of these five kinds of ILs/ $\mathrm{CH}_{3} \mathrm{CN}$ binary system also decreases as the polyethylene glycol chain length increases (Figure 6). 
Table 3. Experimental density for ionic liquids $\left(\mathrm{g} \mathrm{m}^{-3}\right)$

\begin{tabular}{|c|c|c|c|c|}
\hline $\mathbf{T} / \mathbf{K}$ & $\mathbf{1}$ & $\mathbf{2}$ & $\mathbf{3}$ & $\mathbf{4}$ \\
\hline 283.15 & 1.3728 & 1.3279 & 1.2859 & 1.2733 \\
\hline 293.15 & 1.3610 & 1.3226 & 1.2783 & 1.2668 \\
\hline 303.15 & 1.3524 & 1.3169 & 1.2708 & 1.2584 \\
\hline 313.15 & 1.3436 & 1.3103 & 1.2618 & 1.2479 \\
\hline 323.15 & 1.3351 & 1.3048 & 1.2542 & 1.2415 \\
\hline 333.15 & 1.3285 & 1.2995 & 1.2479 & 1.2322 \\
\hline
\end{tabular}

Table 4. Experimental density for ILs $/ \mathrm{CH}_{3} \mathrm{CN}$ system $\left(\mathrm{g} \mathrm{m}^{-3}\right)$

\begin{tabular}{|c|c|c|c|c|c|}
\hline $\mathbf{T} / \mathbf{K}$ & 1 & 2 & 3 & 4 & 5 \\
\hline \multicolumn{6}{|c|}{$\mathrm{C}=0.01 \mathrm{~g} \mathrm{~mL}^{-1}$} \\
\hline 283.15 & 0.7976 & 0.7965 & 0.7952 & 0.7950 & 0.7948 \\
\hline 293.15 & 0.7903 & 0.7860 & 0.7850 & 0.7846 & 0.7813 \\
\hline 303.15 & 0.7777 & 0.7767 & 0.7748 & 0.7736 & 0.7727 \\
\hline 313.15 & 0.7674 & 0.7654 & 0.7639 & 0.7627 & 0.7623 \\
\hline 323.15 & 0.7564 & 0.7549 & 0.7544 & 0.7530 & 0.7521 \\
\hline 333.15 & 0.7468 & 0.7439 & 0.7433 & 0.7429 & 0.7425 \\
\hline \multicolumn{6}{|c|}{$\mathrm{C}=0.02 \mathrm{~g} \mathrm{~mL}^{-1}$} \\
\hline 283.15 & 0.8046 & 0.8033 & 0.8017 & 0.8007 & 0.7962 \\
\hline 293.15 & 0.7940 & 0.7924 & 0.7916 & 0.7896 & 0.7888 \\
\hline 303.15 & 0.7811 & 0.7808 & 0.7796 & 0.7782 & 0.7768 \\
\hline 313.15 & 0.7698 & 0.7690 & 0.7674 & 0.7665 & 0.7656 \\
\hline 323.15 & 0.7623 & 0.7612 & 0.7602 & 0.7595 & 0.7588 \\
\hline 333.15 & 0.7513 & 0.7507 & 0.7486 & 0.7474 & 0.7437 \\
\hline \multicolumn{6}{|c|}{$\mathrm{C}=0.04 \mathrm{~g} \mathrm{~mL}^{-1}$} \\
\hline 283.15 & 0.8158 & 0.8109 & 0.8101 & 0.8079 & 0.8068 \\
\hline 293.15 & 0.8067 & 0.8017 & 0.8012 & 0.8005 & 0.7910 \\
\hline 303.15 & 0.79 & 99 & 0.7 & 0.7 & 0.7875 \\
\hline 313.15 & 0.7850 & 0.7787 & 0.7783 & 0.7771 & 0.7767 \\
\hline 323.15 & 0.7746 & 0.7689 & 0.7684 & 0.7673 & 0.7665 \\
\hline 333.15 & 0.7645 & 0.7587 & 0.7582 & 0.7571 & 0.7569 \\
\hline \multicolumn{6}{|c|}{$\mathrm{C}=0.06 \mathrm{~g} \mathrm{~mL}^{-1}$} \\
\hline 283.15 & 0.8281 & 0.8227 & 0.8222 & 0.8194 & 0.8046 \\
\hline 293.15 & 0.8188 & 0.8117 & 0.8101 & 0.8097 & 0.7940 \\
\hline 303.15 & 0.8059 & 0.7998 & 0.7984 & 0.7978 & 0.7811 \\
\hline 313.15 & 0.7947 & 0.7883 & 0.7862 & 0.7853 & 0.7698 \\
\hline 323.15 & 0.7887 & 0.7826 & 0.7800 & 0.7795 & 0.7623 \\
\hline 333.15 & 0.7762 & 0.7689 & 0.7678 & 0.7660 & 0.7513 \\
\hline
\end{tabular}

Moreover, Figure 7 proves that for the same kind of ionic liquids, the density of the system increases as the ionic liquid concentration increases.

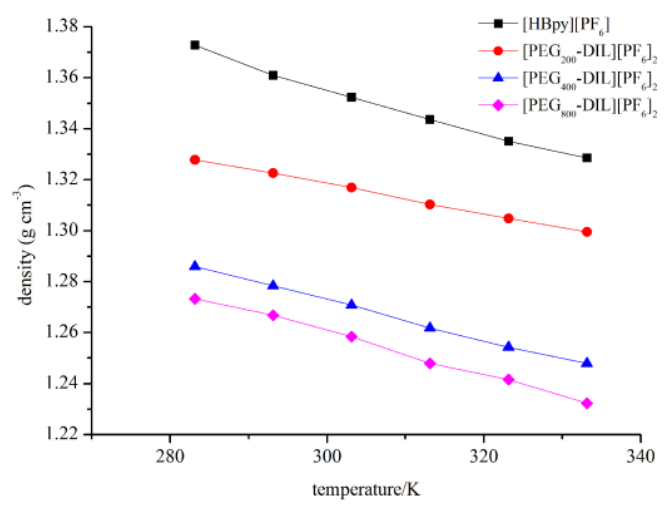

Figure 5. Experimental density of ionic liquids from 283.15 to $333.15 \mathrm{k}$

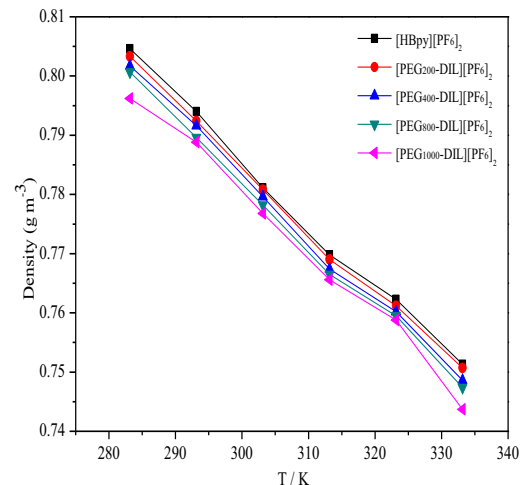

Figure 6. The density for ILs $+\mathrm{MeCN}$ when $\mathrm{C}=0.02 \mathrm{~g} \mathrm{~mL}^{-1}$

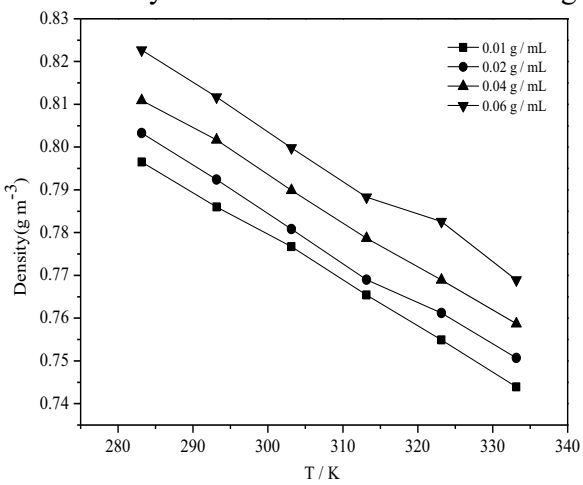

Figure7. Experimental density for different concentration of $\left[\mathrm{PEG}_{200}-\mathrm{DIL}\right]\left[\mathrm{PF}_{6}\right]_{2}+\mathrm{CH}_{3} \mathrm{CN}$

\subsection{Density data correlations}

3.4.1 Correlation of density as a function of temperature of five ionic liquids solution of $\mathrm{CH}_{3} \mathrm{CN}$

The correlation with temperature can be expressed using the following linear equation [17]:

$$
\ln \rho=-\alpha T+\beta
$$

Where, $\rho\left(\mathrm{g} \mathrm{m}^{3}\right)$ and $T(\mathrm{~K})$ denote density and temperature, respectively. The characteristic parameters $\alpha$ $\left(\mathrm{g} \mathrm{cm}^{-1}\right)$ and $\beta\left(10^{3} \mathrm{~g} \mathrm{~cm}^{-3}\right)$ can be determined from the intercept and slope of the corresponding lines; The best linear fitting $\alpha$ and $\beta$ for each investigated ILs and ARD (average relative deviation) between calculated values and experimental data are presented in Table 6 and 7. 
Table 5. The correlated parameters for the densities of ionic liquids

\begin{tabular}{|c|c|c|c|c|}
\hline ILs & $\alpha /\left(\mathrm{g} \subset \mathrm{cm}^{-1}\right)$ & $\beta /\left(10^{3} \mathrm{~g} \square \mathrm{cm}^{-3}\right)$ & ARD (\%) & $\mathbf{R}^{2}$ \\
\hline 1 & 1.3786 & -0.86 & 0.1275 & 0.9799 \\
\hline 2 & 1.3340 & -0.57 & 0.0760 & 0.9849 \\
\hline 3 & 1.2955 & -0.82 & 0.1779 & 0.9675 \\
\hline 4 & 1.2829 & -0.84 & 0.1423 & 0.9762 \\
\hline
\end{tabular}

Table 6. The correlated parameters for the densities of ILs + $\mathrm{CH}_{3} \mathrm{CN}$

\begin{tabular}{|c|c|c|c|c|}
\hline $\begin{array}{c}\mathrm{c} / \\
\left(\mathrm{g} \mid \mathrm{mL}^{-1}\right)\end{array}$ & $\alpha /\left(\mathrm{g}_{\mathbf{c m}}{ }^{-1}\right)$ & $\begin{array}{c}\beta / \\
\left(10^{3} \mathrm{~g} \mathrm{~cm}^{-3}\right)\end{array}$ & $\begin{array}{l}\text { ARD } \\
(\%)\end{array}$ & $\mathbf{R}^{2}$ \\
\hline \multicolumn{5}{|c|}{$[\mathrm{HBpy}]\left[\mathrm{PF}_{6}\right]_{2}+\mathrm{CH}_{3} \mathrm{CN}$} \\
\hline 0.01 & 0.8093 & -1.0457 & 0.0917 & 0.9970 \\
\hline 0.02 & 0.8145 & -1.0654 & 0.1490 & 0.9953 \\
\hline 0.04 & 0.8270 & -1.0414 & 0.0614 & 0.9989 \\
\hline 0.06 & 0.8382 & -1.0314 & 0.1506 & 0.9932 \\
\hline \multicolumn{5}{|c|}{$\left[\mathrm{PEG}_{200}-\mathrm{DIL}\right]\left[\mathrm{PF}_{6}\right]_{2}+\mathrm{CH}_{3} \mathrm{CN}$} \\
\hline 0.01 & 0.8073 & -1.0502 & 0.0455 & 0.9993 \\
\hline 0.02 & 0.8131 & -1.0526 & 0.1150 & 0.9968 \\
\hline 0.04 & 0.8219 & -1.0589 & 0.0587 & 0.9990 \\
\hline 0.06 & 0.8324 & -1.0509 & 0.1572 & 0.9929 \\
\hline \multicolumn{5}{|c|}{$\left[\mathrm{PEG}_{400}-\mathrm{DIL}\right]\left[\mathrm{PF}_{6}\right]_{2}+\mathrm{CH}_{3} \mathrm{CN}$} \\
\hline 0.01 & 0.8057 & -1.0349 & 0.0318 & 0.9997 \\
\hline 0.02 & 0.8120 & -1.0626 & 0.1167 & 0.9963 \\
\hline 0.04 & 0.8211 & -1.0534 & 0.0633 & 0.9988 \\
\hline 0.06 & 0.8316 & -1.0700 & 0.1558 & 0.9933 \\
\hline \multicolumn{5}{|c|}{$\left[\mathrm{PEG}_{800}-\mathrm{DIL}\right]\left[\mathrm{PF}_{6}\right]_{2}+\mathrm{CH}_{3} \mathrm{CN}$} \\
\hline 0.01 & 0.8053 & -1.0463 & 0.0421 & 0.9996 \\
\hline 0.02 & 0.8105 & -1.0529 & 0.1124 & 0.9962 \\
\hline 0.04 & 0.8195 & -1.0423 & 0.0842 & 0.9972 \\
\hline 0.06 & 0.8300 & -1.0574 & 0.1406 & 0.9936 \\
\hline \multicolumn{5}{|c|}{$\left[\mathrm{PEG}_{1000}-\mathrm{DIL}\right]\left[\mathrm{PF}_{6}\right]_{2}+\mathrm{CH}_{3} \mathrm{CN}$} \\
\hline 0.01 & 0.1478 & -1.3389 & 0.1868 & 0.9975 \\
\hline 0.02 & 0.8080 & -1.0391 & 0.1868 & 0.9913 \\
\hline 0.04 & 0.8143 & -0.9537 & 0.1876 & 0.9842 \\
\hline 0.06 & 0.8145 & -1.0654 & 0.1490 & 0.9953 \\
\hline
\end{tabular}

Table 6 summarizes that the ARDs of the correlations of density data of ILs are less than $0.1779 \%$; the overall ARD is $0.131 \%$ for a total of 24 data points, table 7 shows that all the ARD of binary system is less than $0.736 \%$ and the correlation coefficients are all above 0.99 . Moreover, the total ARD is $0.159 \%$; above results prove that the equation can be well associated with density values of these five ionic liquids.

\section{Conclusions}

According to the study, the solubilities and hydroscopicity of five ILs were influenced by the polarity of solvents and chain length of PEG. With the increase of the polarity of the solvent and the length of PEG chain, the solubilities and hydroscopicity increased. Because the PEG chain length increases, then the stereo-hindrance effect decreases and van der Waals force also increases. However, $[\mathrm{HBpy}]\left[\mathrm{PF}_{6}\right]$, which is without PEG-fragment, was influenced by multi-effect of the fluorine atoms and the absence of stereo-hindrance effect, didn't follow this regularity. On the basis of the density data, the densities of the investigated ILs are in the range of 1.2322 to $1.3728 \mathrm{~g} \mathrm{~cm}^{-3}$ over a temperature range of 288.15 to $333.15 \mathrm{~K}$. The longer the alkyl chain on the cation, the lower density of the ionic liquid is. The density decreased with the rising temperature; under the same temperature, the density of the ionic liquid increased with the increase of its chain length. And the measured density data were correlated with equations with good results.

\section{References}

1. K.K. Laali. Ionic liquids in Synthesis. 2003, 1752 (2003)

2. J.D. Holbrey, K.R. Seddon. Clean Products and Processes. 1, 223 (1999)

3. T. Welton, Chem. Rev. 99, 2071 (1999)

4. K. Huang, X. Han, X. Zhang, D.W. Armstrong, Anal. Bioanal. Chem. 389, 2265 (2007)

5. M.M. Cecchini, A. Bendjeriou, N. Mnasri, C. Charnay, F.D. Angelis, F. Lamaty, et al., New J. Chem. 38, 6133 (2014)

6. W.W. Ho, K. Li, Sep. Sci. Technol. 40, 1245 (2005)

7. A.G. Fadeev, M.M. Meagher, Chem. Commun.3, 295 (2001)

8. Y. Pei, J. Wang, K. Wu, X. Xuan, X. Lu, Sep. Purif. Technol. 64, 288 (2009)

9. N. Papaiconomou, G. Vite, N. Goujon, J. Lévêque, I. Billard, Green. Chem. 14, 2050 (2012)

10. H. Zeng, Y. Wang, J. Kong, C. Nie, Y. Yuan, Talanta. 83, 582 (2010)

11. J. Salminen, N. Papaiconomou, R.A. Kumar, J. Lee, J. Kerr, J. Newman, et al., Fluid Phase Equilib. 261, 421 (2007)

12. L. Nie, H. Song, S. Yao, Anal. Lett. 48, 1257 (2015)

13. Y. Shu, X. Chen, J. Wang, Talanta. 81, 637 (2010)

14. E.J. González, B. González, E.A. Macedo, J. Chem. Thermodyn. 86, 96 (2015)

15. N. Van Meurs, G. Somsen, J. Solution. Chem. 22, 427 (1993)

16. Y. Huo, S. Xia, P. Ma, J. Chem. Eng. Data. 52, 2077 (2007)

17. R. Yusoff, M.K. Aroua. J. Chem. Eng. Data. 58, 240 (2013) 